\title{
Improved Control of Wind Power Generation Based on Variable Structure Slide Mode and Inverse System
}

\author{
Jiyong Zhang ${ }^{1,2 *}$, Guohai Liu ${ }^{1}$ and Jinjie $\mathrm{Li}^{2}$ \\ ${ }^{1}$ Institute of Electrical \& Information Engineering, \\ Jiangsu University, Zhenjiang, 212013, P. R. China \\ ${ }^{2}$ Institute of Energy \& Power Engineering, \\ Yangzhou University, Yangzhou, 225009, China \\ zjy@yzu.edu.cn
}

\begin{abstract}
The traditional Double-fed Wind Generation used a vector control method, but it was more dependent on motor parameters, once the parameters had changed, the effect of the system control would be affected. This paper proposed a control method based on inverse system, through the inverse system theory, the structure of its state's equation, obtaining the structure of the inverse system, the establishment of Wind Power Generation closed-loop control system was established at last. Some simulations were proceeded to verify the controller's performance. When the system operates in VSCF and the phase voltage drops, the simulation results show that the control system can control the DC link voltage steadily, maintain unity power factor, achieve the decoupling of active and reactive power. It proves that this control method used in variable speed constant frequency wind power has good performance.
\end{abstract}

Key words: DFIG; Inverse system; VSS; VSCF

\section{Introduction}

During the last two decades, the wind power generation have increased significantly. Wind energy has been noted as the fastest growing renewable power generation technology in the world,with an annual growth rate in excess of $30 \%$ and a foreseeable penetration of $12 \%$ of global eletricity demand by 2020 [1, 2]. The doubly-fed generator (DFIG) is very attractive for adjustable speed constant frequency (ASCF) generators with limited speed range.

At the present time, wind power systems based on DFIG, controlled by means of back to back power converters, constitute almost the $50 \%$ of the installed wind turbines worldwide in on-shore applications. This provdies flexibility of operation in sub-synchronous and supersynchronous speeds both in the generating and motoring modes. The layout of a wind turbine based on this technology is shown in Figure $1[3,4]$. 


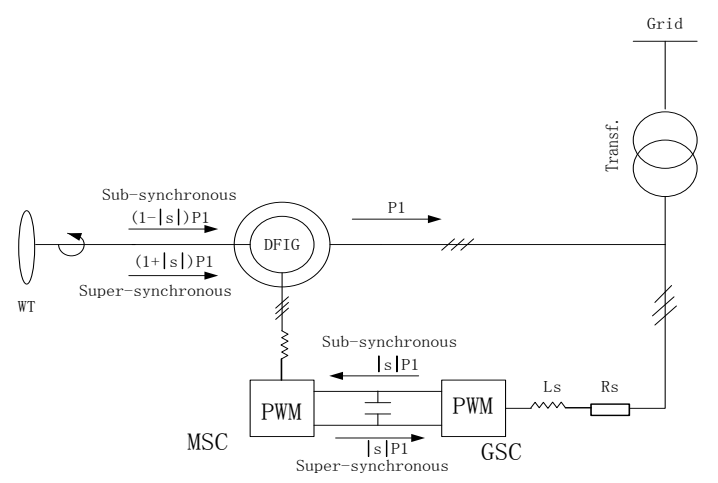

Figure 1. The basic structure of DFIG wind power

The DFIG is the traditional multi-variable, nonlinear and coupled system, and control accuracy, dynamic performance of such system can not be meeted by classic control. At present, the major control strategy is vector control based on linearized model. For the DC-link voltage maintainence and unit power factor operation, conventional approach for the control of the DFIG is the implementation of grid voltage or virtual flux orientation in the grid side independently. And the relatively independent stator field orientation in the machine side is adopted to realize the decoupling of active and reactive power $[5,6,7]$. While the power converter of machine side and grid side, DFIG are comparatively interactional whole, so due to the above two aspects for doubly-fed wind power generators are organic links as a whole, so asunder the physical contact by independent control each other, only rely on nearby system steady point to design the controller, the system parameter changes or large disturbances will directly affect the stability of the wind turbine operation. The classic vector control system of the wind power generators depending on the system parameters, can be difficult to achieve high performance of active power and reactive power decoupling control when large disturbances come to pass. On the other hand, due to rapid changes the randomness of the wind energy, so in variable speed constant frequency doubly-fed wind power generation system, the slip power is often varying, which is the change of the load with respect to grid side converter severely. The grid side converter is required in drastic load change to maintain stability of the dc link voltage. Dc link voltage static stability and dynamic regulating speed is essential to the operation characteristics of wind power system. In order to make the grid side of the converter can achieve excellent performance; the design of the controller is the key. There are literature presents an inverse system control theory research control strategy of doubly-fed wind power generators, but the control algorithm are complex, and depends on the system parameters considerably $[8,9]$. There is literature has been only designed the grid side PWM converter using the nonlinear inverse system control independently, can better realize the dc link voltage and the grid side of the power factor control, but the inverse system of machine side PWM converter doesn't design [10].

Above of all, this paper propose a strategy from the perspective of whole system that combine dual PWM converter with the unified mathematical model of doubly-fed wind power generator, by using feedback linearization of nonlinear system [11], inverse system 
control theory is used to control dc link voltage, grid side power factor, active power and reactive power of DFIG. The four parameters are decoupled, and exponential convergence law of variable structure sliding mode control strategy is used to build a closed-loop control. The control performance of designed wind power generation system is verified by simulation and experiment. Results show that the system of DFIG has good robustness and dynamic response.

\section{The Unified Mathematical Model of DFIG and Dual PWM Converter}

In the practical operation, the dual PWM converter and DFIG is considerable interaction. So the grid side converter, machine side converter and DFIG are needed to think about an integrated whole. From the perspective of system integration that to build its mathematical model is very necessary. For doubly-fed wind power generation system to achieve high performance control of DFIG, from the perspective of system integration to implement control, the unified model of DFIG and converter that as a whole must be established.

The circuit principle diagram of doubly-fed wind power generation system is shown in Figure 2. System consists of a DFIG and a back to back PWM converter. The back to back voltage source PWM converter is composed of a grid side converter and an machine side converter (or called rotor side converter) with a large electrolytic capacitor in the dc-link. Between grid side converter and grid has a filter, generally consists of L filter (or LCL filter), is used to eliminate harmonics caused by converter, and also, in the middle of the rotor side converter with DFIG rotor has a L filter, to eliminate the harmonic, but it's impedance is very small, often ignored.

\subsection{DFIG Wind Turbines and Machine Side PWM Mathematical Model}

DFIG stator and rotor are assumed to be the three-phase symmetric winding, uniformly distributed within the circular motor, air gap is uniform distribution circuit and magnetic circuit is symmetrical, ignore the hysteresis, eddy current loss and iron loss. From the dynamic point of view, the leakage inductance of the stator and rotor has the same effect on the motor. So if put the stator leakage inductance in the rotor circuit, known as induction motor $\tau$ model, will form a different representation with respect to Park Mode. $\tau$ Model is especially suitable for analysis of motor maintain a constant stator flux amplitude control. The equivalent circuit diagram that is shown in Figure 2 by using $\tau$ Model of DFIG and machine

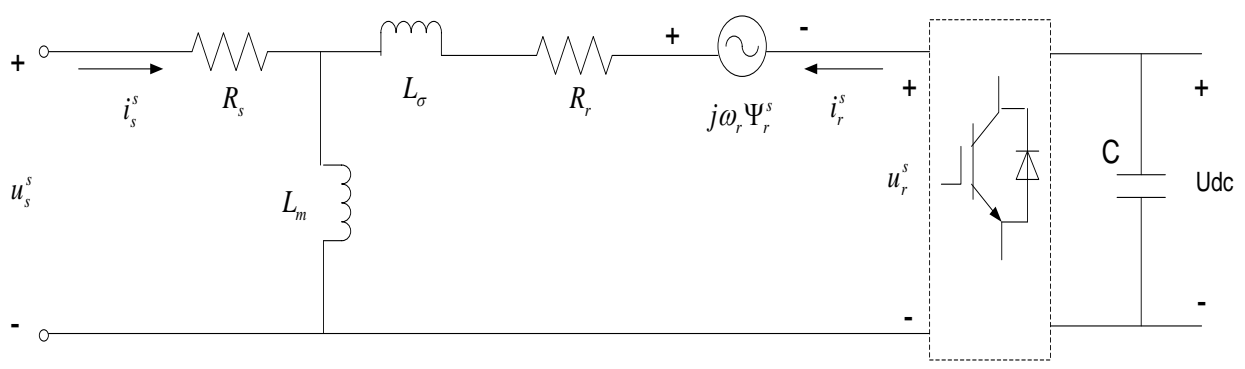

Figure 2. $\tau$ Model equivalent circuit of DFIG and machine side PWM converter 
From the equivalent circuit diagram, equations of doubly-fed motor combination machine side PWM converter can be obtained in the stator and rotor respectively coordinates:

$$
\left\{\begin{array}{l}
u_{s}^{s}=R_{s} i_{s}^{s}+\frac{d \Psi_{s}^{s}}{d t} \\
u_{r}^{r}=R_{r} i_{r}^{r}+\frac{d \Psi_{r}^{r}}{d t}-j \omega_{r} \Psi_{r}^{s} \\
u_{r}^{s}=S_{m} U_{d c}
\end{array}\right.
$$

Where $S_{m}$ is switching function of machine side converter, $U_{d c}$ is the dc link voltage.

Transition to the synchronous rotating coordinate system:

$$
\left\{\begin{array}{l}
u_{s}=R_{s} i_{s}+\frac{d \Psi_{s}}{d t}+j \omega_{1} \Psi_{s} \\
u_{r}=R_{r} i_{r}+\frac{d \Psi_{r}}{d t}+j \omega_{s} \Psi_{r} \\
u_{r}=S_{m} U_{d c}
\end{array}\right.
$$

where $\omega_{s}=\omega_{1}-\omega_{r}$ is slip angular velocity, active power of the rotor side $P_{r}=3 \operatorname{Re}\left[u_{r} i_{r}^{*}\right]$.

Flux equation:

$$
\left\{\begin{array}{l}
\Psi_{s}=L_{m}\left(i_{s}+i_{r}\right)=L_{m} i_{m s} \\
\Psi_{r}=L_{m} i_{s}+\left(L_{\sigma}+L_{m}\right) i_{r}=L_{\sigma} i_{r}+\Psi_{s}
\end{array}\right.
$$

Electromagnetic torque equation: $T_{e}=3 n_{p} I_{m}\left[\Psi_{s} i_{r}^{*}\right]$

\subsection{Mathematical Model of Grid Side PWM Converter}

Variable speed constant frequency wind power system requires grid side converter to control dc link voltage stable, to keep unit power factor operation. Combined with the $\tau$ Model of doubly-fed motor Model and the dual PWM converter with grid side filter, the equivalent structure diagram of the DFIG wind power system is shown as follow. 


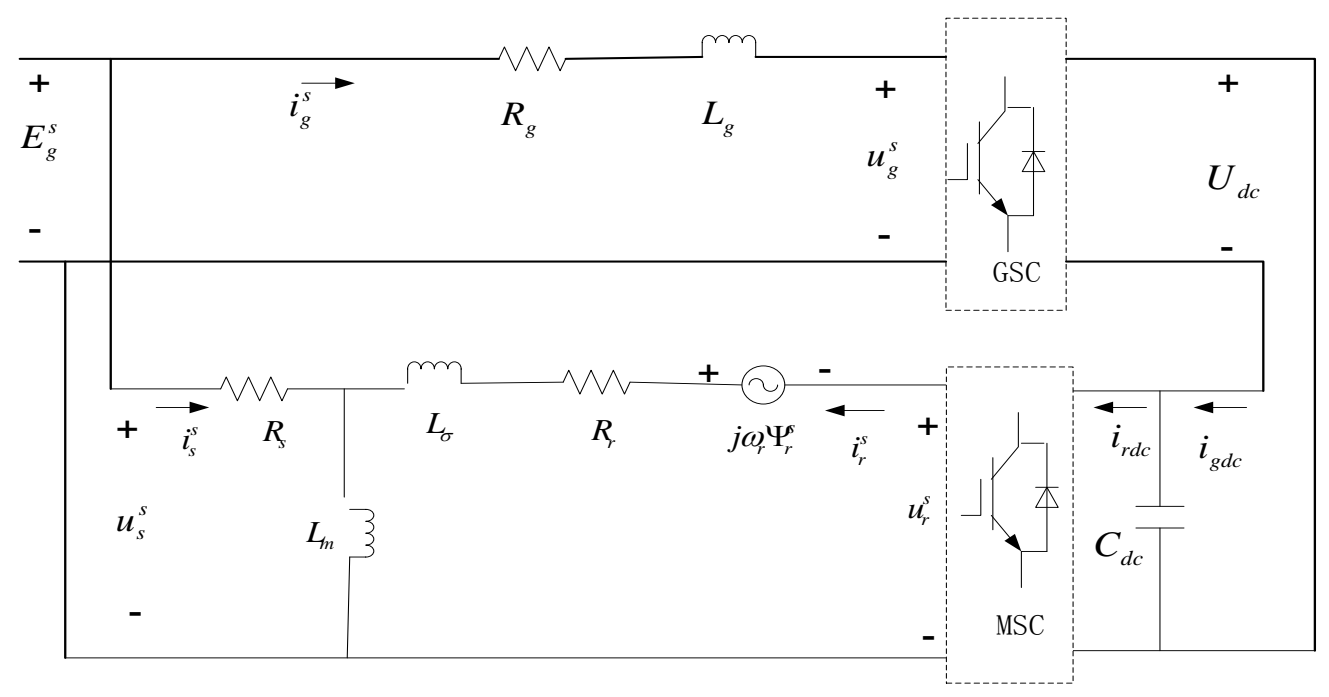

Figure 3. The unified equivalent structure of DFIG

According to Figure 3, mathematical model of grid side PWM converter is:

$$
\left\{\begin{array}{l}
E_{g}^{s}=R_{g} i_{g}+L_{g} \frac{d i_{g}^{s}}{d t}+u_{g}^{s} \\
u_{g}^{s}=S_{g} U_{d c}
\end{array}\right.
$$

Where $S_{g}$ is switching function of grid side converter.

Ignore loss of converter, the energy of grid side converter $P_{g}$ and the energy of rotor side converter $P_{r}$ determine the energy that stored in the dc-link capacitor, so the dc link voltage equations is:

$$
\begin{aligned}
& C_{d c} U_{d c} \frac{d U_{d c}}{d t}=P_{g}-P_{r} \\
& P_{g}=3 \operatorname{Re}\left\lfloor u_{g} i_{g}^{*}\right\rfloor
\end{aligned}
$$

\subsection{The Unified Mathematical Model of DFIG Wind Power System}

When DFIG connect the grid, the stator voltage is the same as the grid voltage, transit the mathematical model of the doubly-fed wind power generation system to the dq coordinate system:

$$
\begin{aligned}
& \left\{\begin{array}{l}
E_{s d}=R_{s} i_{s d}+p \Psi_{s d}-\omega_{1} \Psi_{s q} \\
E_{s q}=R_{s} i_{s q}+p \Psi_{s q}+\omega_{1} \Psi_{s d}
\end{array}\right. \\
& \left\{\begin{array}{l}
u_{r d}=R_{r} i_{r d}+p \Psi_{r d}-\left(\omega_{1}-\omega_{r}\right) \Psi_{r q}=S_{m d} U_{d c} \\
u_{r q}=R_{r} i_{r q}+p \Psi_{r q}+\left(\omega_{1}-\omega_{r}\right) \Psi_{r d}=S_{m q} U_{d c}
\end{array}\right.
\end{aligned}
$$




$$
\left\{\begin{array}{l}
u_{g d}=E_{g d}-R_{g} i_{g d}-L_{g} p i_{g d}+\omega_{1} L_{g} i_{g q}=S_{g d} U_{d c} \\
u_{g q}=E_{g q}-R_{g} i_{g q}-L_{g} p i_{g q}-\omega_{1} L_{g} i_{g d}=S_{g q} U_{d c}
\end{array}\right.
$$

Considering calculation simple and the precision of the model, the rotor dc side power replace the rotor side power, then

$$
\begin{aligned}
& C_{d c} U_{d c} p U_{d c}=P_{q}-P_{r}=\left(u_{g q} i_{g q}+u_{g d} i_{g d}\right)-U_{d c} i_{r d c} \\
& \frac{J}{n_{p}} p \omega_{r}=T_{e}-T_{L} \\
& T_{e}=n_{p} L_{m}\left(i_{s q} i_{r d}-i_{s d} i_{r q}\right)
\end{aligned}
$$

where is $p$ differential operator,

$$
\left\{\begin{array}{l}
P_{g}=E_{g q} i_{g q}+E_{g d} i_{g d} \\
P_{r}=u_{r q} i_{r q}+u_{r d} i_{r d}=U_{d c} i_{r d c}
\end{array}\right.
$$

From mathematical model, the doubly-fed wind power generation system is actually a 8 order system, with eight state variables, the grid connection of doubly-fed wind power generation system, can select $i_{s d}, i_{s q}, i_{r d}, i_{r q}, i_{g d}, i_{g q}, U_{d c}, \omega_{r}$ as state variables, select the four switching function $S_{g d}, S_{g q}, S_{m d}$ and $S_{m q}$ of back to back PWM converter as control input.

Based on instantaneous power theory, under the $\mathrm{dq}$ coordinate system, the output of instantaneous active power and reactive power by doubly-fed wind power system is:

$$
\left\{\begin{array}{l}
P_{s}=u_{s d} i_{s d}+u_{s q} i_{s q} \\
Q_{s}=u_{s q} i_{s d}-u_{s d} i_{s q}
\end{array}\right.
$$

For grid connection of doubly-fed wind power system stable operation, must maintain grid side unit power factor operation $\left(i_{g q}=0\right)$ and dc link voltage constant. So active power $\mathrm{P}$ and reactive power Q, $U_{d c}$ and grid side $i_{g q}$ are selected as output variables.

According to the unified mathematical model of doubly-fed wind power generation system, respectively, the system mathematical model of DFIG combined with machine side PWM converter, grid side PWM converter combined with grid side filter under the corresponding coordinate system mathematical model need to be analyze.

\subsubsection{Mathematical Model of DFIG and Machine Side PWM Converter Based On the Stator Flux Orientation}

Consider the stator flux orientation, ignore the stator resistance, then

$$
\left\{\begin{array}{l}
\Psi_{s d}=\Psi_{s}=E_{g} / \omega_{1} \\
\Psi_{s q}=0
\end{array}\right.
$$


$\left\{\begin{array}{c}u_{s d}=0 \\ u_{s q}=E_{g}\end{array}\right.$

Select the following state variables and input variables and output variables:

$$
\begin{aligned}
X_{m} & =\left[\begin{array}{ll}
x_{m 1} & x_{m 2}
\end{array}\right]^{T}=\left[\begin{array}{ll}
i_{r d} & i_{r q}
\end{array}\right]^{T} \\
U_{m} & =\left[\begin{array}{ll}
u_{m 1} & u_{m 2}
\end{array}\right]^{T}=\left[\begin{array}{ll}
u_{r d} & u_{r q}
\end{array}\right]^{T} \\
Y_{m} & =\left[\begin{array}{ll}
y_{m 1} & y_{m 2}
\end{array}\right]^{T}=\left[\begin{array}{ll}
P_{s} & Q_{s}
\end{array}\right]^{T} \\
& =\left[\begin{array}{ll}
u_{s d} i_{s d}+u_{s q} i_{s q} & u_{s q} i_{s d}-u_{s d} i_{s q}
\end{array}\right]^{T}=\left[\begin{array}{ll}
E_{g} i_{s q} & E_{g} i_{s d}
\end{array}\right]^{T}
\end{aligned}
$$

Can write the corresponding state space expression is as follows:

$$
\begin{aligned}
& \left\{\begin{array}{l}
\dot{x}_{m 1}=-\frac{R_{r}}{\sigma L_{r}} x_{m 1}+\omega_{s} x_{m 2}+\frac{1}{\sigma L_{r}} u_{m 1} \\
\dot{x}_{2}=\omega_{s} L_{r} x_{m 1}-\frac{R_{r}}{\sigma L_{r}} x_{m 2}-\frac{L_{m}}{L_{s}} E_{g}+\frac{1}{\sigma L_{r}} u_{m 2}
\end{array}\right. \\
& \left\{\begin{array}{l}
y_{m 1}=-\frac{L_{m}}{L_{s}} E_{g} x_{m 2} \\
y_{m 1}=\frac{E_{g}}{L_{s}}\left(\Psi_{s}-L_{m} x_{m 1}\right)
\end{array}\right.
\end{aligned}
$$

Here is $\sigma=1-\frac{L_{m}^{2}}{L_{s} L_{r}}$ factor for the leakage reactance of DFIG.

\subsubsection{Mathematical Model of Line Filter Combined with DC Bus and Grid Side PWM Converter Based On Grid Voltage Orientation}

Under the grid voltage orientation, $E_{g d}=E_{g}, u_{g q}=\mathrm{O}$, so the power of grid side PWM converter is simplified to:

$$
\left\{\begin{array}{l}
P_{g}=E_{g d} i_{g d}+E_{g q} i_{g q}=E_{g} i_{g d} \\
Q_{g}=E_{g q} i_{g d}-E_{g d} i_{g q}=-E_{g} i_{g q}
\end{array}\right.
$$

For the requirements of grid side PWM control, select the following state variables and input variables and output variables:

$$
\begin{aligned}
& X_{g}=\left[\begin{array}{lll}
x_{g 1} & x_{g 2} & x_{g 3}
\end{array}\right]^{T}=\left[\begin{array}{lll}
i_{g d} & i_{g q} & U_{d c}
\end{array}\right]^{T} \\
& U_{g}=\left[\begin{array}{ll}
u_{g 1} & u_{2}
\end{array}\right]^{T}=\left[\begin{array}{ll}
u_{g d} & u_{g q}
\end{array}\right]^{T} \\
& Y_{g}=\left[\begin{array}{ll}
y_{g 1} & y_{g 2}
\end{array}\right]^{T}=\left[\begin{array}{ll}
Q_{g} & U_{d c}
\end{array}\right]^{T}
\end{aligned}
$$


Can write the corresponding state space expression is as follows:

$$
\begin{aligned}
& \left\{\begin{array}{l}
\dot{x}_{g 1}=-\frac{R_{g}}{L_{g}} x_{g 1}+\omega_{1} x_{g 2}+\frac{E_{g}}{L_{g}}-\frac{1}{L_{g}} u_{g 1} \\
\dot{x}_{g 2}=-\omega_{1} x_{g 1}-\frac{R_{g}}{L_{g}} x_{g 2}-\frac{1}{L_{g}} u_{g 2} \\
\dot{x}_{g 3}=\frac{E_{g}}{C_{d c} x_{g 3}} x_{g 1}-\frac{i_{r d c}}{C_{d c}}
\end{array}\right. \\
& \left\{\begin{array}{l}
y_{g 1}=-E_{g} x_{g 2} \\
y_{g 2}=x_{g 3}
\end{array}\right.
\end{aligned}
$$

\section{The Design of Variable Structure Sliding Mode for DFIG Wind Power System Based On Inverse System}

The so-called inverse system control is to be achieved by constructing $\alpha$-order inverse system, the original system is compensated to a linear transitive relation that is a decoupling and pseudo-linear composite system [14, 15]. According to the system that has been linearized or linear decoupling subsystem, it can design the closed-loop controller. A composite controller (Compound Control System) is shown in Figure 4.

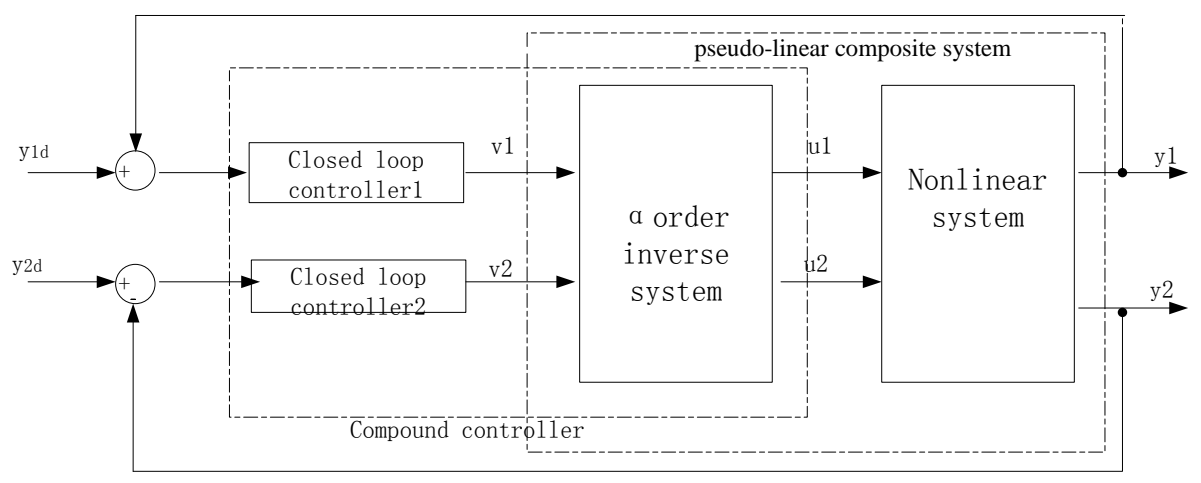

\section{Figure 4. The controller formed by $\alpha$-order inversesystem and closed-loop control}

Sliding mode variable structure (VSS) control for nonlinear and uncertain systems is a effective method. In this paper, closed-loop controller can be achieved by the VSS controller. It is designed according to exponential reaching law, the classic switching function is replaced of continuous function, can improve the dynamic performance in normal operation range effectively.

Only a reversible nonlinear system can be use of inverse system method for precise linearization. The reversibility doubly-fed wind power generation system must be analyzed. According to the analysis of the mathematical model of doubly-fed wind power generation system, the corresponding mathematical model of the reversibility and nonlinear controller are researched. 


\subsection{The Machine Side Nonlinear Controller Research Based On Inverse System}

Derivate two outputs variables in the equation (21), can judge the input content in the output equation whether or not.

$$
\begin{aligned}
& \dot{y}_{m 1}=\frac{L_{m}}{L_{s}} E_{g}\left(-\omega_{s} L_{r} x_{m 1}+\frac{R_{r}}{\sigma L_{r}} x_{m 2}+\frac{L_{m}}{L_{s}} E_{g}\right)-\frac{L_{m}}{\sigma L_{s} L_{r}} E_{g} u_{m 2} \\
& \dot{y}_{m 2}=\frac{L_{m}}{L_{s}} E_{g}\left(\frac{R_{r}}{\sigma L_{r}} x_{m 1}-\omega_{s} x_{m 2}\right)-\frac{L_{m}}{\sigma L_{s} L_{r}} E_{g} u_{m 1}
\end{aligned}
$$

Rewritten as $\dot{Y}_{m}=A_{m}(x)+E_{m}(x) U_{m}$, then

$$
E_{m}(x)=\left[\begin{array}{cc}
0 & -\frac{L_{m}}{\sigma L_{s} L_{r}} E_{g} \\
-\frac{L_{m}}{\sigma L_{s} L_{r}} E_{g} & 0
\end{array}\right]
$$

Obviously is $E_{m}(x)$ singular, so it has inverse system, work it out and get $u_{m 1}, u_{m 2}$.Corresponding inverse model is as follows:

$$
\begin{aligned}
& {\left[\begin{array}{l}
u_{m 1} \\
u_{m 2}
\end{array}\right]=\left[\begin{array}{l}
R_{r} x_{m 1}-\sigma L_{r} \omega_{s} x_{m 2} \\
-\sigma L_{r}^{2} \omega_{s} x_{m 1}+R_{r} x_{m 2}+\frac{\sigma L_{r} L_{m}}{L_{s}} E_{g}
\end{array}\right]+\left[\begin{array}{cc}
0 & -\frac{\sigma L_{s} L_{r}}{L_{m} E_{g}} \\
-\frac{\sigma L_{s} L_{r}}{L_{m} E_{g}} & 0
\end{array}\right]\left[\begin{array}{l}
\dot{y}_{m 1} \\
\dot{y}_{m 2}
\end{array}\right]} \\
& \operatorname{Take}\left[\begin{array}{l}
\varphi_{m 1} \\
\varphi_{m 1}
\end{array}\right]=\left[\begin{array}{l}
\dot{y}_{m 1} \\
\dot{y}_{m 2}
\end{array}\right] \text {, then } \\
& {\left[\begin{array}{l}
u_{m 1} \\
u_{m 2}
\end{array}\right]=\left[\begin{array}{l}
R_{r} x_{m 1}-\sigma L_{r} \omega_{s} x_{m 2} \\
-\sigma L_{r}^{2} \omega_{s} x_{m 1}+R_{r} x_{m 2}+\frac{\sigma L_{r} L_{m}}{L_{s}} E_{g}
\end{array}\right]+\left[\begin{array}{cc}
0 & -\frac{\sigma L_{s} L_{r}}{L_{m} E_{g}} \\
-\frac{\sigma L_{s} L_{r}}{L_{m} E_{g}} & 0
\end{array}\right]\left[\begin{array}{l}
\varphi_{m 1} \\
\varphi_{m 2}
\end{array}\right]}
\end{aligned}
$$

To achieve the power control of the doubly-fed wind power generation system has good dynamic response performance, the corresponding nonlinear controller is designed using variable structure sliding mode theory. Define the following sliding mode switching function

$$
\begin{aligned}
& \boldsymbol{S}_{\boldsymbol{m}}=\left[\begin{array}{ll}
S_{m 1} & \left.S_{m 2}\right]^{T}
\end{array}\right. \\
& \left\{\begin{array}{l}
S_{m 1}=e_{P}=P_{s}^{*}-P_{s} \\
S_{m 2}=e_{Q}=Q_{s}^{*}-Q_{s}
\end{array}\right.
\end{aligned}
$$

Where $\mathrm{P} *, \mathrm{Q} *$ are the active power and reactive power reference respectively; $\mathrm{P}$ and $\mathrm{Q}$ are the active power and reactive power by real-time calculating. Derivate switching function $\mathrm{S}$ with time, then 


$$
\left\{\begin{array}{l}
\dot{S}_{m 1}=\dot{e}_{P}=-\dot{P}_{s} \\
\dot{S}_{m 2}=\dot{e}_{Q}=-\dot{Q}_{s}
\end{array}\right.
$$

Combined with the mathematical model of the doubly-fed motor, differential equation of switching function is shown as bellow:

$$
\dot{S}_{m}=F_{m}+D_{m} U_{m}
$$

Where $\boldsymbol{U}_{\boldsymbol{m}}$ is the matrix of control law, coefficient matrix are $\boldsymbol{F}_{\boldsymbol{m}}=\left[F_{m 1} F_{m 2}\right]^{T}$ and $\boldsymbol{D}_{\boldsymbol{m}}, \quad \boldsymbol{U}_{\boldsymbol{m}}$ is the control law

$$
U_{m}=-D^{-1}\left[\begin{array}{c}
F_{m 1}+K_{m 1} S_{m 1}+K_{m 2} \operatorname{sign}\left(S_{m 1}\right) \\
F_{m 2}+K_{m 3} S_{m 2}+K_{m 4} \operatorname{sign}\left(S_{m 2}\right)
\end{array}\right]
$$

Considering the resistance of filter in machine side and eliminating its effect, PI regulator can be use to control the active power and reactive power reference.

\subsection{Nonlinear Controller Research Based on the Grid Side of Inverse System}

Derivate two outputs variables in the equation (27), can judge the input content in the output equation whether or not.

$$
\begin{aligned}
\dot{y}_{g 1} & =-E_{g} \dot{x}_{g 2}=E_{g}\left(\omega_{1} x_{g 1}-\frac{R_{g}}{L_{g}} x_{g 2}-\frac{1}{L_{g}} u_{g 2}\right) \\
\ddot{y}_{g 2} & =\ddot{x}_{g 3}=\frac{E_{g}}{C_{d c} x_{g 3}}\left(\dot{x}_{g 1}-\frac{x_{g 1}}{x_{g 3}} \dot{x}_{g 3}\right)-\frac{1}{C_{d c}} \dot{i}_{r d c} \\
& =\frac{E_{g}}{C_{d c} x_{g 3}}\left[-\frac{R_{g}}{L_{g}} x_{g 1}+\omega_{1} x_{g 2}+\frac{E_{g}}{L_{g}}-\frac{x_{g 1}}{x_{g 3}}\left(\frac{E_{g}}{C_{d c} x_{g 3}} x_{g 1}-\frac{i_{r d c}}{C_{d c}}\right)-\frac{u_{g 1}}{L_{g}}\right]-\frac{1}{C_{d c}} \dot{i}_{r d c}
\end{aligned}
$$

That is $\left[\begin{array}{c}\dot{y}_{g 1} \\ \ddot{y}_{g 2}\end{array}\right]=\left[\begin{array}{c}A_{g 1}(x) \\ A_{g 2}(x)\end{array}\right]+E_{g}(x)\left[\begin{array}{l}u_{g 1} \\ u_{g 2}\end{array}\right]$, where

$$
\begin{aligned}
& A_{g}(x)=\left[\begin{array}{c}
A_{g 1}(x) \\
A_{g 2}(x)
\end{array}\right] \\
& =\left[\begin{array}{c}
E_{g}\left(\omega_{1} x_{g 1}-\frac{R_{g}}{L_{g}} x_{g 2}\right) \\
\frac{E_{g}}{C_{d c} x_{g 3}}\left[-\frac{R_{g}}{L_{g}} x_{g 1}+\omega_{1} x_{g 2}+\frac{E_{g}}{L_{g}}-\frac{x_{g 1}}{x_{g 3}}\left(\frac{E_{g}}{C_{d c} x_{g 3}} x_{g 1}-\frac{i_{r d c}}{C_{d c}}\right)\right]-\frac{1}{C_{d c}} i_{r d c}
\end{array}\right] \\
& E_{g}(x)=\left[\begin{array}{cc}
0 & -\frac{E_{g}}{L_{g}} \\
-\frac{E_{g}}{C_{d c} x_{g 3} L_{g}} & 0
\end{array}\right]
\end{aligned}
$$


Obviously is $E_{g}(x)$ singular, so its inverse system exists, work out the $u_{g 1}, u_{g 2}$ and the corresponding inverse model is as follows:

$$
\begin{aligned}
& {\left[\begin{array}{l}
u_{g 1} \\
u_{g 2}
\end{array}\right]=\left[\begin{array}{c}
\frac{C_{d c} x_{g 3} L_{g}}{E_{g}} A_{g 2}(x) \\
\frac{L_{g}}{E_{g}} A_{g 1}(x)
\end{array}\right]+\left[\begin{array}{cc}
0 & -\frac{C_{d c} x_{g 3} L_{g}}{E_{g}} \\
-\frac{L_{g}}{E_{g}} & 0
\end{array}\right]\left[\begin{array}{l}
\dot{y}_{g 1} \\
\ddot{y}_{g 2}
\end{array}\right]} \\
& \operatorname{Take}\left[\begin{array}{l}
\varphi_{g 1} \\
\varphi_{g 1}
\end{array}\right]=\left[\begin{array}{l}
\dot{y}_{g 1} \\
\ddot{y}_{g 2}
\end{array}\right] \text {, then } \\
& {\left[\begin{array}{l}
u_{g 1} \\
u_{g 2}
\end{array}\right]=\left[\begin{array}{c}
\frac{C_{d c} x_{g 3} L_{g}}{E_{g}} A_{g 2}(x) \\
\frac{L_{g}}{E_{g}} A_{g 1}(x)
\end{array}\right]+\left[\begin{array}{cc}
0 & -\frac{C_{d c} x_{g 3} L_{g}}{E_{g}} \\
-\frac{L_{g}}{E_{g}} & 0
\end{array}\right]\left[\begin{array}{l}
\varphi_{g 1} \\
\varphi_{g 2}
\end{array}\right]}
\end{aligned}
$$

Define the following sliding mode switching function $: S_{g}=\left[S_{g 1} S_{g 2}\right]^{T}$

$$
\left\{\begin{array}{c}
S_{g 1}=e_{Q_{g}}=Q_{g}^{*}-Q_{g} \\
S_{g 2}=e_{U_{d c}}=U_{d c}^{*}-U_{d c}
\end{array}\right.
$$

where $U_{d c}{ }^{*} 、 Q^{*}$, are the commands of dc link voltage and reactive power, here $Q^{*}=0 ; U_{d c}$ and $Q_{g}$ are real-time dc bus voltage and reactive power of grid side. Derivate $\mathrm{S}$ with time, then

$$
\left\{\begin{array}{c}
\dot{S}_{g 1}=\dot{e}_{Q_{g}}=-\dot{Q}_{g} \\
\dot{S}_{g 2}=\dot{e}_{U_{d c}}=-\dot{U}_{d c}
\end{array}\right.
$$

Combined with the mathematical model of the doubly-fed motor, differential equation of switching function is shown as follows.

$\dot{S}_{g}=F_{g}+D_{g} U_{g}$

Where the $\boldsymbol{U}_{\boldsymbol{g}}$ is matrix of control law. The coefficient matrix are $\boldsymbol{F}_{\boldsymbol{g}}=\left[F_{g 1} F_{g 2}\right]^{T}$ and $\boldsymbol{D}_{\boldsymbol{g}}, \boldsymbol{U}_{\boldsymbol{g}}$ as the control law:

$U_{g}=-D_{g}^{-1}\left[\begin{array}{c}F_{g 1}+K_{g 1} S_{g 1}+K_{g 2} \operatorname{sign}\left(S_{g 1}\right) \\ F_{g 2}+K_{g 3} S_{g 2}+K_{g 4} \operatorname{sign}\left(S_{g 2}\right)\end{array}\right]$

To eliminating the references changes varying with system parameters, PI regulator can be used. 


\section{The Structure of Control System}

This designed structure based on inverse system structure is shown as in Figure 5:

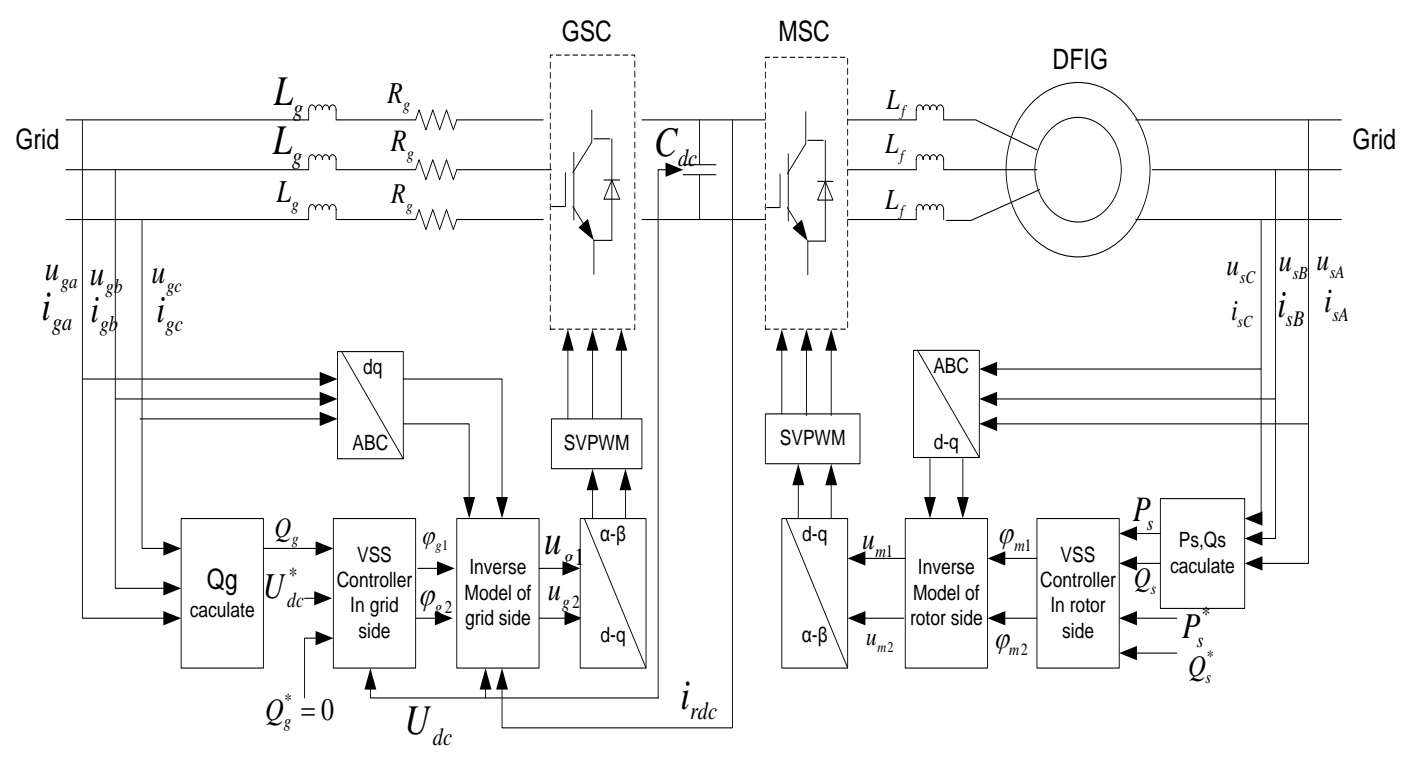

Figure 5. The diagram of the proposed inverse system

By measuring voltage, current with the sensors, active and reactive power can be attained.

\section{The Simulation and Experimental}

\subsection{System Simulation}

In order to validate the correctness of the pseudo linear inverse system control scheme, in this paper, the control system are simulated by using Matlab/Simulink.

The simulation parameters:

Doubly-fed motor rated power : $7.5 \mathrm{kw}$; Stator resistance : $0.435 \Omega$; Leakage inductance of the rotor : $2 \mathrm{mH}$; Rotor resistance : $0.816 \Omega$; Leakage inductance of the rotor : $69.31 \mathrm{mH}$; Inertia of rotation: $0.089 \mathrm{~kg} / \mathrm{m}^{2}$; Effective value of grid line voltage : $690 \mathrm{~V}$,DC link voltage : $1200 \mathrm{~V}$; Line resistance $\operatorname{Rg}=0.05 \Omega$, Line inductance $\mathrm{Lg}=6 \mathrm{Mh}$ : Dc bus capacitor : $\mathrm{C}=2200 \mathrm{uf}$.

As shown in Figure 6 and Figure 7, when the active power and reactive power are regulated independently, the control strategy used in this paper is clearly better than the conventional vector control method, the power has no obvious fluctuation, the dc bus voltage has little fluctuation. 


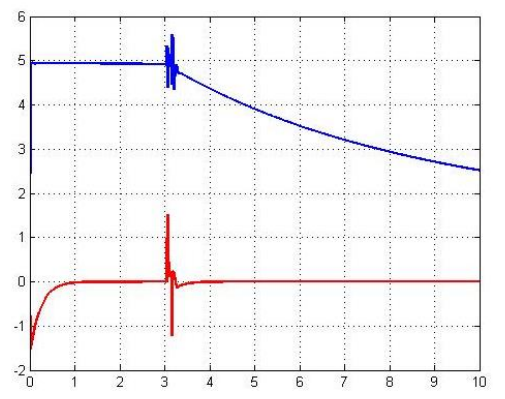

(a)Active and reactive power by classic vector control.

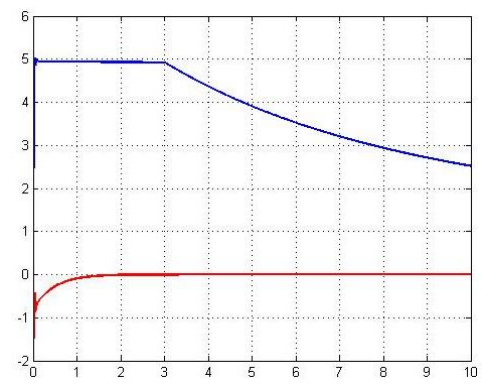

(b) Active and reactive power by VSS and inverse system.

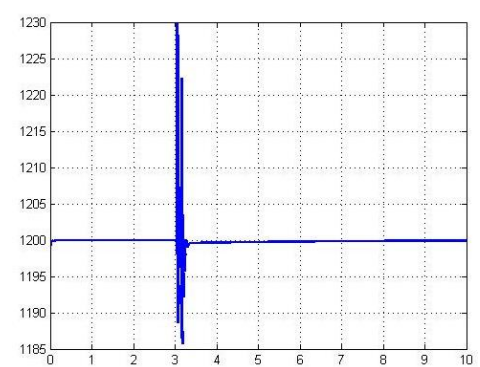

(c) DC-link voltage by classic vector control.

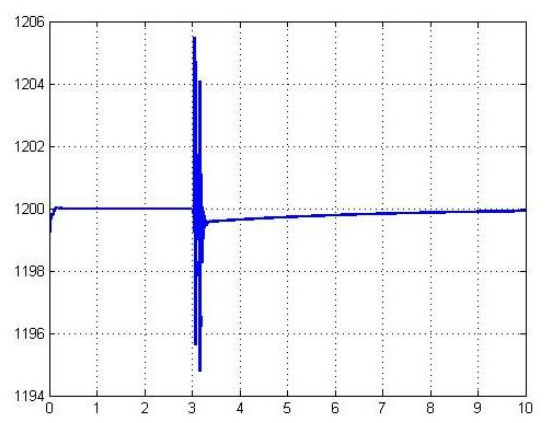

(d) DC-link voltage by VSS and inverse system.

Figure 6. $P$ regulating and $Q=0$, power and $D C$-link voltage wave 
International Journal of Control and Automation

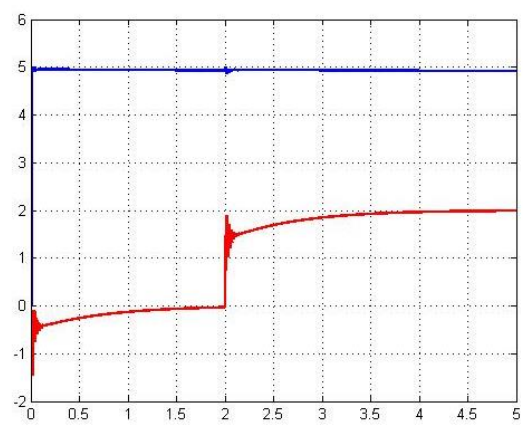

(a) Active and reactive power by classic vector control.

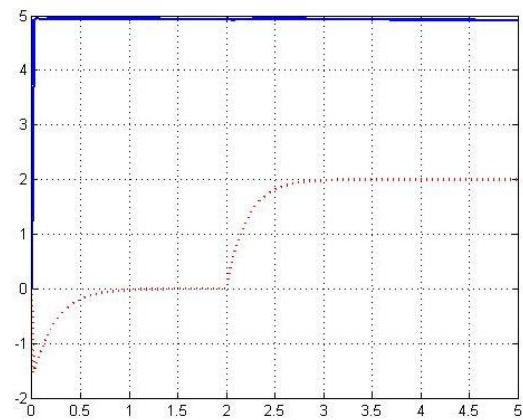

(b) Active and reactive power by VSS and inverse system.

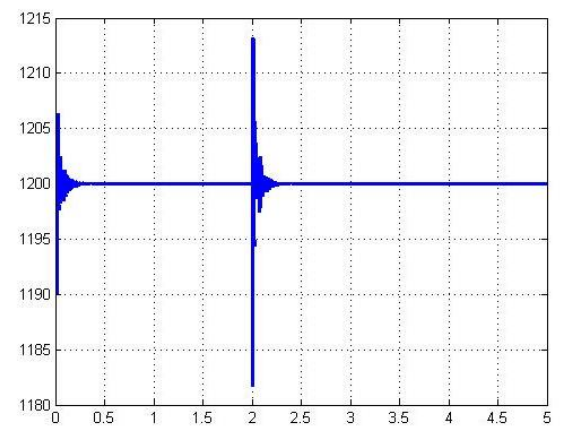

(c) DC-link voltage by classic vector control.

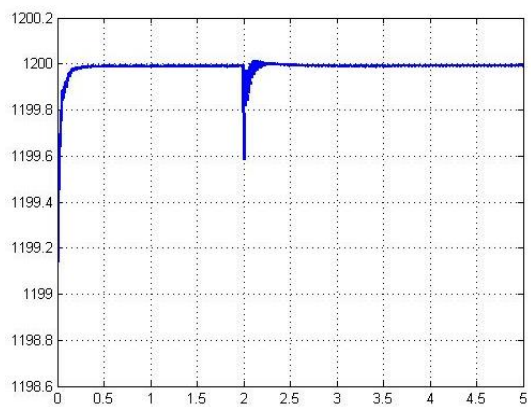

(d) DC-link voltage by VSS and inverse system.

Figure 7. $P$ regulating and $Q$ vary, power and $D C$-link voltage wave 


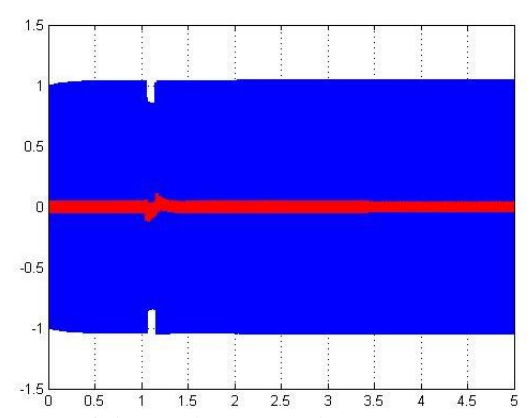

(a) Grid. A phase and current wave.

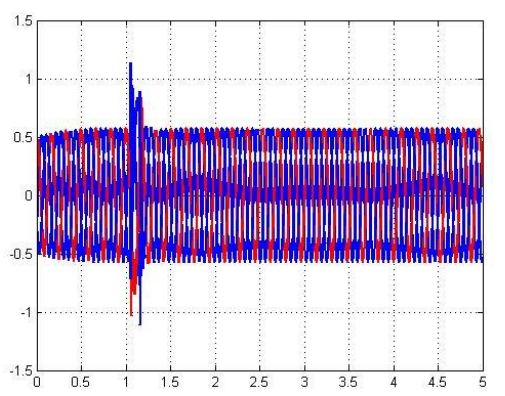

(b) Three-phase rotor current by classic vector control.

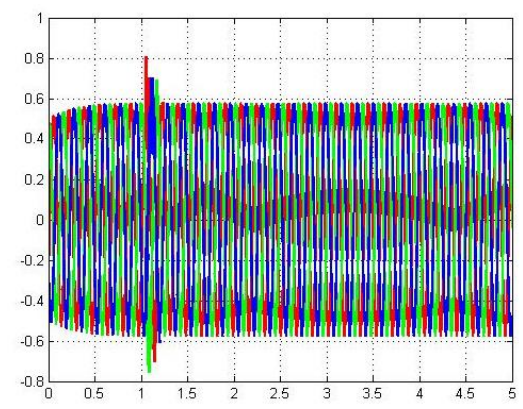

(c) Three-phase rotor current by VSS and inverse system.

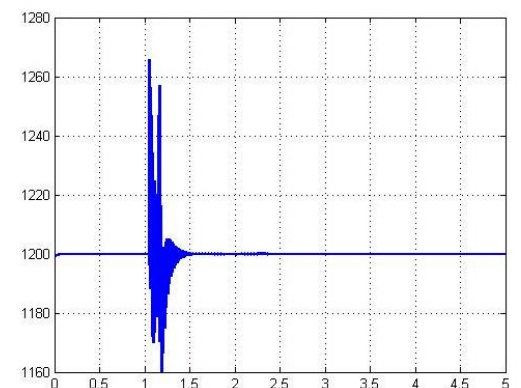

(d) DC-link voltage by classic vector control. 


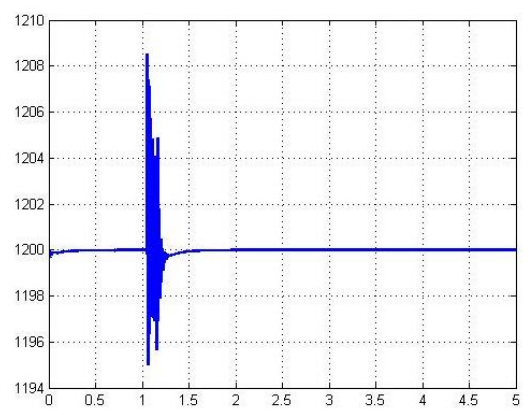

(e) DC-link voltage wave by VSS and inverse system.

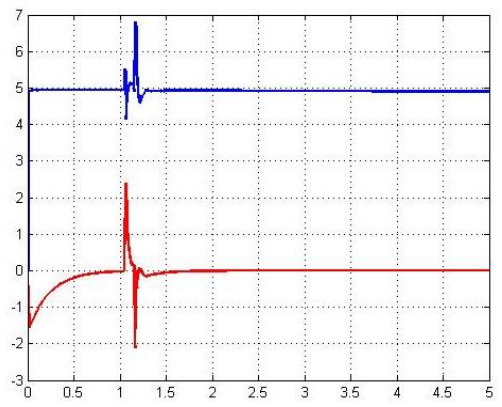

(f) Active and reactive power by classic vector control.

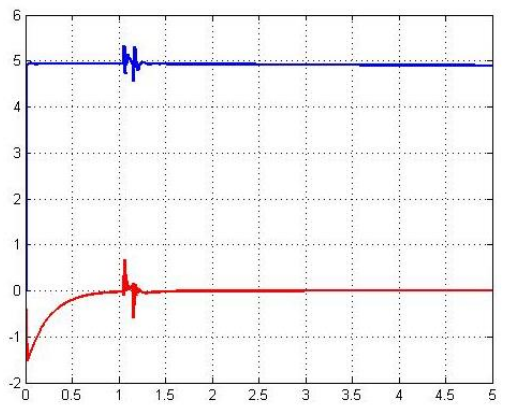

(g) Active and reactive power by VSS and inverse system.

\section{Figure 8 . Three phase grid voltage sag $20 \%$, grid side A phase voltage and current, rotor current, DC-link voltage, active and reactive power wave}

When grid A phase voltage drop $20 \%$ in 1.05 seconds, and recover in 1.15 seconds. As shown in Figure 8, the rotor current is increased, DC-link voltage is oscillating, active power and reactive power is also affected by grid voltage sag, but we can see from the figure, doubly-fed wind power system used the variable structure slide mode and inverse system in the paper, rotor current fluctuation is greatly reduced. DC-link voltage fluctuation is limited to small range, after the fault clearance can be recovered quickly. This will be conducive to safe and reliable operation of the wind turbines. In Figure $8(\mathrm{f})(\mathrm{g})$ can be found that, active power and reactive power also have small fluctuations. The simulation results show that the control method in this paper has good dynamic stability. 


\subsection{Experimental Verification}

System parameters:

Doubly-fed motor rated power: 7.5KW; Rated line voltage: 380V; Rated current: 20A;

Rated speed: $750 \mathrm{r} / \mathrm{min} \quad ; n_{p}=4$;Inertia of rotation: $\mathrm{J}_{\mathrm{m}}=0.2 \mathrm{kgm}^{2} \quad$;Stator resistance: $R_{s}=1.25 \Omega$; Rotor resistance: $R_{r}=0.3549 \Omega$; Rotor inductance: $L_{l r}=0.00974566 H$; Mutual inductance: $L_{m}=0.06775133 H$;Grid side line inductance: $L=0.001 \mathrm{H}$;Resistance: $R=0.1 \Omega$.;DC-link voltage $u_{d c}=650 \mathrm{~V}$; Rated line voltage of Grid side: 380 v; Rated frequency $50 \mathrm{~Hz}$; PWM converter frequency :6400 Hz.

Experimental results are as follows:

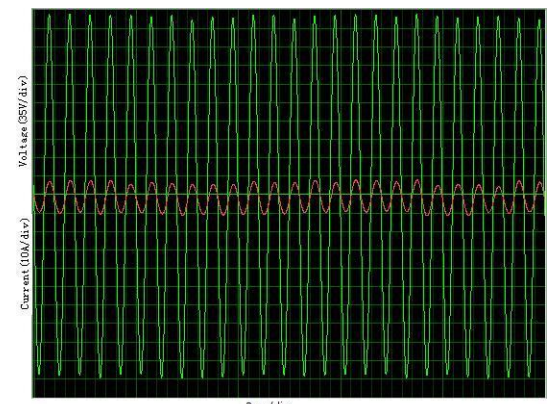

(a) under sub-synchronous.

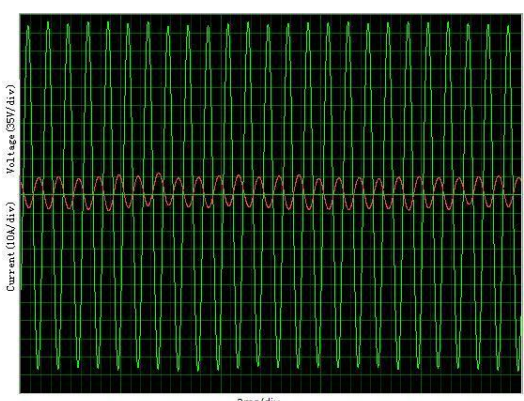

(b) under super-synchronous.

Figure 9. Grid side A phase voltage and current under sub- and supersynchronous

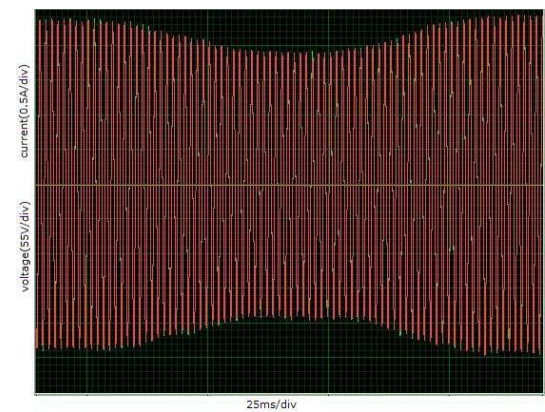

(a) Grid sideA phase and current.

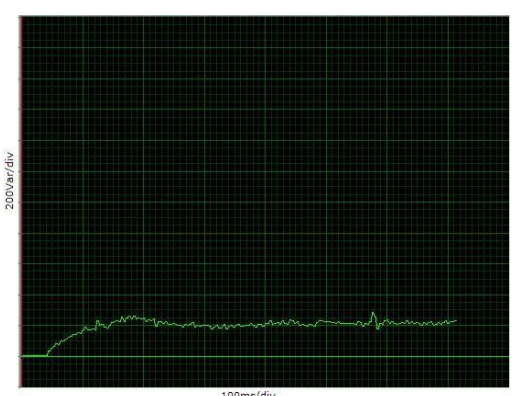

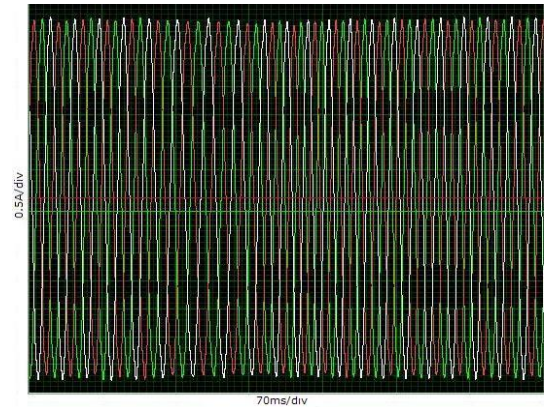

(b) Three-phase stator current.

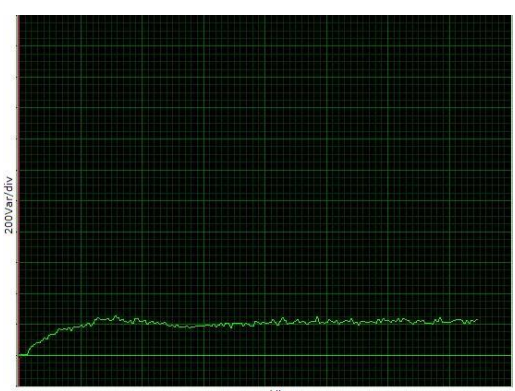

(c) Reactive power by classic vector control. (d) Reactive power by VSS \& inverse system. 


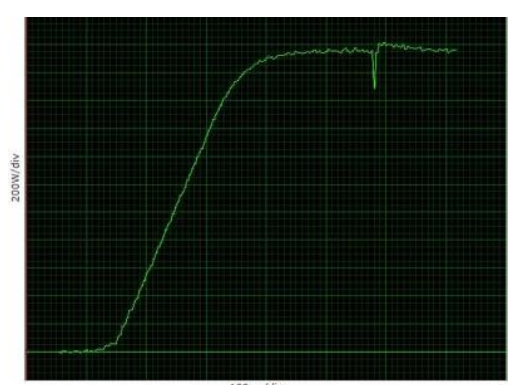

(e) Active power by classic vector control.

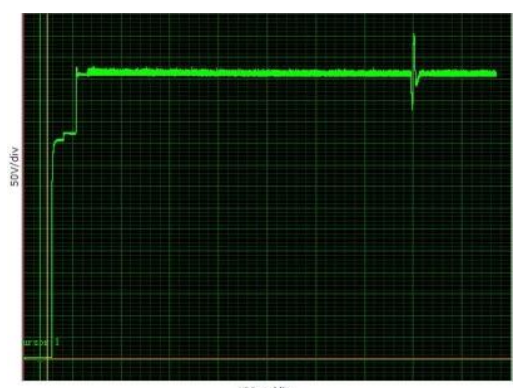

(g)Udc under classic vector control.

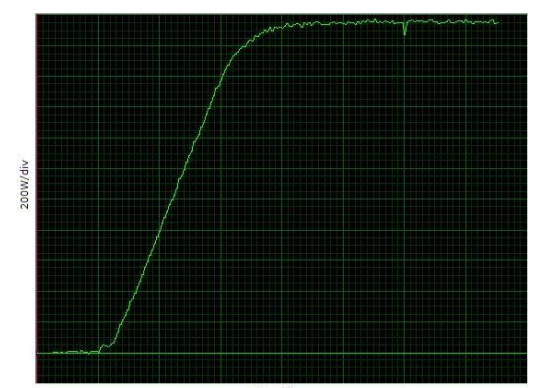

(f) Active power by VSS \& inverse system.

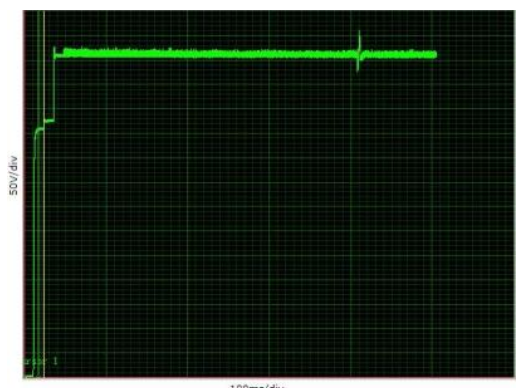

(h) Udc under VSS \& inverse system.

\section{Figure 10. Three phase grid voltage sag $20 \%$, grid side A phase voltage and current, stator current, DC-link voltage, active and reactive power}

It can be seen from Figure 9, the control strategy using in this paper, can effectively realize the wind turbines grid side unit power factor operation under the sub-synchronism and supersynchronous. When A phase of grid voltage drop 20\%, it can be seen from Figure 10, using inverse system with VSS control strategy, the stator current is relatively stable, active power and reactive power fluctuation is small, especially the dc bus voltage fluctuation does not exceed $60 \mathrm{~V}$, able to recover quickly, has good robustness. The control strategy prosposed in this paper is verified superior to the classic vector control strategy again.

\section{Conclusion}

Based on the unified mathematical model of variable speed constant frequency wind power generation system, on the basis of through the inverse system theory and control model, constructs the pseudo linear control system, through the dq current decoupling control, realize the stator active and reactive power decoupling, the grid side of the dc bus voltage and reactive power decoupling. The variable structure sliding mode controllers improve the system dynamic performance and robustness. Through simulation and experiments on the proposed control method is verified. The results show that the proposed nonlinear decoupling control strategy has good dynamic characteristic and stability. 


\section{References}

[1] R. Chedid, "Intelligent Control for Wind Energy Conversion Systems", Wind Engineering, vol. 22, no. 1, (1998), pp. 1-16.

[2] T. Ackermann and L. Soder, "An overview of wind energy-status 2002", Renewable and Sustainable Energy Reviews", vol. 6, no. 1-2,(2002), pp. 67-127.

[3] A. M. Trzynadlowski and S. F. Legowaki, "Minimum-loss Vector PWM Strategy for Three-phase Inverters", IEEE Trans. Power Electron, vol. 9, no. 2, (1994), pp. 26-34.

[4] S. Ramire, "Nolinear P-I controller design for switchmode DC-to-DC power converters", IEEE Trans. Circuit Syst., vol. 38, no. 4, (1991), pp. 410-417.

[5] J. Feng and H. Jin, "Novel Modulation Method for Direct Power Control of Three-phase PWM Rectifier", Power Electronics, vol. 40, no. 4, (2006), pp. 9-11.

[6] R. Pena, J. C. Clare and G. M. Asher, "Doubly fed induction genetatot suing back-to-back PWM converters and its application to variable speed wind energy generation", IEEE Proceedings-Electric Power Applications, vol. 143, no. 3, (1996), pp. 231-241.

[7] D. D. Li and C. Chen, "Decoulped Control of Speed and Reactive Power of Doubly-fed Induction Generator", International Conference on Power System Technology, Singapore: IEEE, (2004) November.

[8] K. B. Mohanty, "Input-Output Linearization and Decoupling Control of an Induction Motor Drive", Journal of the Institution of Engineers, vol. 88, no. 2, (2007) February, pp. 45-51.

[9] A. Mullane, G. Lightbody and R. Yacamini, "Comparison of a Casade and Feedback Linearization Scheme for DC Link Votage Control in a Grid Connected Wind Turbin", Proceeding of the $36^{\text {th }}$ Universities Power Engineering Conference, UK: IEEE, (2001) September.

[10] T. Li, Z. Tong and B. Wang, "Direct Power Control of Three Phase PWM Rectifier Based on the Inverse System Theory", Journal of Electric Drive, vol. 38, no. 10, (2008) October, pp. 33-38.

[11] X. Dai, G. Liu and X. Zhang, "AC Drive Based on Neural Network and Inverse System Theory”, Beijing: China Machine Press, (2007).

[12] W. E. Leithead, S. D. Salle and D. Reardon, "Role and objictives of control for wind turbines", IEEE Proc. Part C, (1991), pp. 135-148.

[13] P. Rioual, H. Poliquen and J. p. Louis, "Non-linear control of PWM rectifier by feedback linearization and exact PWM control”, Conf. Rec. IEEE PESC'94, (1994), pp. 1095-1102.

[14] T. S. Lee, "Nolinear state feedback control design for three-phase PWM boost rectifiers using extended linearization", IEEE Proc. Power Appl., (2003), pp. 546-554.

[15] J. Matas, M. Castilla and J. M. Guerrero, "Feedback Linearization of Direct-Drive Syschronous Wind Turbin via a Sliding Mode Approach", IEEE Trans. On Power Electronics, vol. 23, no. 3, (2008) March, pp. 1093-1103.

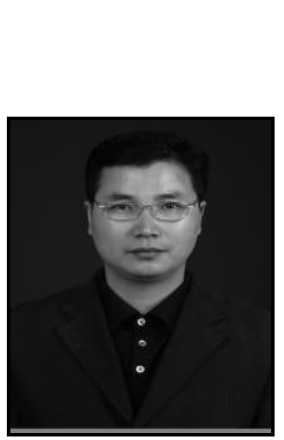

\section{Authors}

Jiyong Zhang received the B.Sc, M.Sc degree in electrical engineering in 1996 and 2003 from JiangSu University in China. He is an Associate Professor in YangZhou University. Now he prepares his Ph.D. Thesis at Jiangsu University, China. His research interests are power electronics, application of power electronics to power system and advanced control techniques applied to renewable energy.

Guohai Liu received Ph.D Degree in electrical engineering in 2001 from Southeast University, China. Now he is a Professor in JiangSu University. His main research interests are advanced control techniques, power-factor-correction techniques and distributed power generation.

Jinjie Li received the B.Sc degree in electrical engineering in 2012 from YangZhou University in China. Now he prepares his M.Sc Thesis at YangZhou University, China. His research interests are application of power electronics to power system and advanced control techniques applied to renewable energy. 
International Journal of Control and Automation Vol.6, No.5 (2013) 